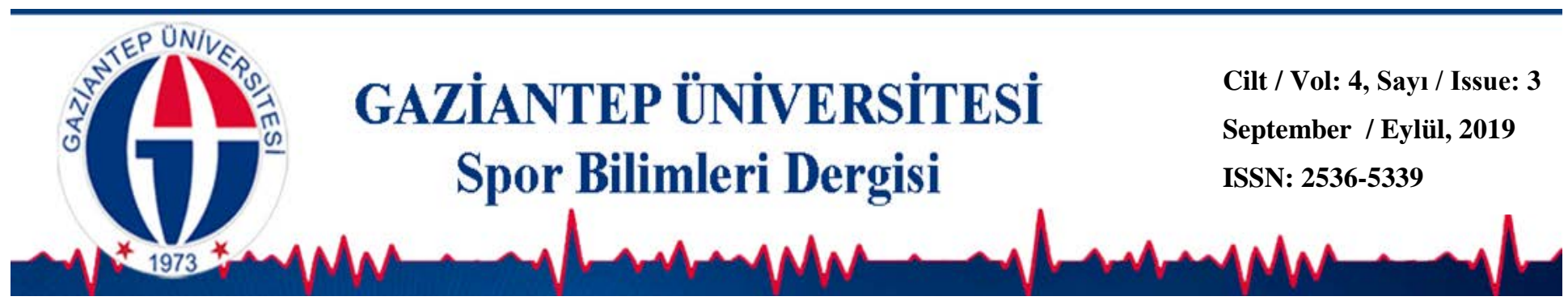

\title{
Bilgisayar Oyunu Oynama Süresinin Uyku Kalitesi, El ve Ayak Reaksiyon Hızı ve Fiziksel Aktivite Seviyesine Etkisi
}

\author{
Faruk ÇALIŞKAN ${ }^{1 *}$ (D) \\ Çetin SAYACA ${ }^{1}$ (D) \\ ${ }^{1}$ Üsküdar Üniversitesi, Sağlık Bilimleri Fakültesi Fizyoterapi Rehabilitasyon Bölümü, ISTANBUL
}

DOI: $10.31680 /$ gaunjss.558006

Orijinal Makale / Original Article

Geliş Tarihi / Received: 25.04.2019 Kabul Tarihi / Accepted: 18.07.2019 Yayın Tarihi / Published: 22.09.2019

\section{Öz}

Bu çalışmada, bilgisayar oyunu oynama süresinin uyku kalitesi, el reaksiyon hızı ve fiziksel aktivite seviyesi arasındaki ilişkinin test edilmesi amaçlanmıştır. Çalışmaya 18-25 yaş aralığında oyun oynayan 31 (19E, 12K) ve oyun oynamayan 30 (16K, 14E) olmak üzere toplam 61 birey çalışmaya dahil edilmiştir. Çalışmaya katılan kişilerin yaş ortalamaları ve standart sapmaları oyun oynamayanlar için $23,096 \pm 2,005$ ve oyun oynayanlar için

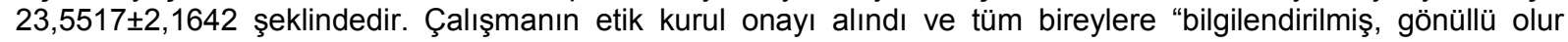
formu" imzalatılmıştır. Bireylerin oyun oynama süreleri ağır, orta, hafif olarak sınıflandırımıştır. Fiziksel aktivite seviyeleri Uluslararası Fiziksel Aktivite Anketi ile uyku kaliteleri Pittsburgh Uyku Kalite İndeksi ile el reaksiyon hızı ise Nelson el ve ayak reaksiyon testi ile değerlendirilmiştir. Çalışmamızda oyun oynayan ve oynamayan bireyler karşılaştırıldığında fiziksel aktivite seviyesi ve uyku kalitesi arasında fark olmadığı ortaya çıkmıştır $(p>0,05)$. Fakat el reaksiyon hızı karşılaştırıldığında anlamlı farklılık olduğu gözlenmiştir $(p<0,01)$. Oyun oynayan bireylerin el reaksiyon hızı oyun oynamayanlara göre daha iyi olduğu sonucuna ulaşılmıştır. Oyun çeşidi ile oyun oynama süresi arasında ise anlamlı fark olmadığı tespit edilmiştir ( $p>0.005)$. Elde edilen sonuçlar doğrultusunda, bilgisayar oyunu oynamak el reaksiyon hızını geliştirebilir ancak fiziksel aktivite ve uyku kalitesini bozabileceği sonucuna ulaşıımıştır. Ancak her iki grupta fiziksel aktivite düzeyi ve uyku kalitesi arasında fark olmaması gençlerin sedanter yaşama doğru ilerlediğini ve uyku kalitelerinin de azaldığını göstermiştir.

Anahtar kelimeler: Bilgisayar Oyunları, Bilgisayar Oyunları Oynama Süresi, El Reaksiyon Hızı, Fiziksel Aktivite Seviyesi, Uyku Kalitesi.

\section{The Effect of Computer Game Play Time on Sleep Quality, Hand Reaction Speed and Physical Activity Level}

\begin{abstract}
This study was planned to assess the effect of computer game play time on sleep quality, hand reaction speed and physical activity level. A total of 61 individuals were included in the study, including 31 (19e, 12k) and 30 $(16 \mathrm{k}, 14 \mathrm{e})$ playing games $18-25$ years of age. Ethics Committee approval of the study was received. All individuals provided written informed consent before participating in the study. The playing times of individuals were classified as heavy, medium, light. Physical activity levels with international physical Activity questionnaire, Sleep qualities were assessed with Pittsburgh sleep quality index, while hand reaction speed was evaluated by Nelson hand and foot reaction test. In our study, there was no difference between physical activity level and sleep quality compared to individuals who played and did not play $(p>0.05)$. But there was a difference in comparison of hand reaction speed $(p<0.01)$. The hand reaction speed of individuals playing the game was better found. There was a significant difference between game play and game time $(p>0.005)$. It was revealed that hand reaction rates were better for the individuals playing. No difference was found when comparing the physical activity levels and sleep qualities of the two groups. Playing a computer game can improve hand reaction speed but can disrupt physical activity and sleep quality. However, there is no difference between the level of physical activity and the quality of sleep in both groups and shows that young people are progressing towards sedentary life and that their sleep quality may be decreasing. More and more individuals who play different types of computer games are required to study different evaluation methods.
\end{abstract}

Key words: Computer Games, Playing Computer Games Time, Hand Reaction Speed, Physical Activity Level, Sleep Quality

\footnotetext{
* Sorumlu Yazar: Faruk ÇALIŞKAN
}

E-mail: frk-caliskan@hotmail.com 


\section{Giriş}

Çok tercih edilen çevrimiçi çok oyunculu online oyunlar, kullanıcıların birbirleriyle yarışmalarına ve dünyanın her yerindeki insanlarla karşılıklı iletişim kurmalarını sağlayan bilgisayar oyunlarıdır (Gürcan ve ark., 2008). Milyonlarca gencin saatlerce bilgisayar başında kalmasına neden olan bu oyunların popülerliği, her geçtiğimiz gün daha da artmaktadır. Günümüzde gelişen bilgisayar teknolojisinin ve internet kullanımının artması beraberinde birçok problemi de beraberinde getirmektedir. Özellikle gençler arasında yaygınlaşan bilgisayar oyunları ve bunların türevleri artık gençlerde bağımlılık haline gelmektedir. Özelikle internet üzerinden online oynanan oyunlar (MMORPG) kişilere ait oyun içerisindeki karakterleri sahiplenme, geliştirme, diğer oyuncuların karakterleri ile arasındaki seviye farkı gibi birçok teşvik edici faktörün bulunması ciddi rekabet ve pazar ortamı oluşturmaktadır. Sektörün hızlı gelişmesi sonucunda, bu oyunları oynayan bireyler artık sporcu olarak tanımlanmaktadır ve bu oyunlara yönelik dünya çapında kapsamlı turnuvalar düzenlenmektedir.

Gençlerin gündelik hayatta fiziksel aktivitelerinin yerini internet, bilgisayar ve video oyunları almaktadır (Hazar ve Hazar, 2017). Son yıllarda tüm dünyada mücadelesi yoğun bir şekilde devam eden, uzun süreli hareketsiz kalma ve enerji kullanımının düşmesi sonucunda oluşan, birçok hastalığın ortaya çıkmasına zemin hazırlayarak yaşam süresini ve kalitesini olumsuz yönde etkileyen fazla kiloların (obezite) en önemli sebeplerinden biri olarak fiziksel aktivitenin yetersiz olması gösterilmektedir (Daley ve ark., 2006). Dünyada olduğu gibi ülkemizde de obezitenin görülme sıklığı gittikçe artmakta, görülme yaşı düşmekte ve sağlık üzerindeki etkileri ciddi boyutlara ulaşmaktadır. En büyük sebep olarakta internet bağımlılığı ve giderek artan bilgisayar oyunu oynama süresi gösterilmektedir (Baltacı ve ark., 2008). 4 saatten fazla internet kullanan ve ağır kullanıcı olarak sınıflandırılan kullanıcıların yemek öğünlerini atlama ve uyku düzenlerinin bozulması gibi riskli sağlık davranışları göstermektedir. Bu bireylerde uyku problemi ve kilo alma semptomlar daha yüksektir (Kim ve ark., 2010).

Tayland'da 6-14 yaş arası 5.999 çocuk üzerinde yapılan bir araştırmada düşük fiziksel aktiviteye sahip kız çocuklarında; günde 1 saatten fazla bilgisayar kullanmanın ve 2 saatten fazla TV izlemenin; kilo alma riskini arttırdığı tespit edilmiştir (Mayda ve ark., 2015). Aynı çalışmada uzun süre oyun oynayan kişilerde bilişsel ve 
psikolojik sorunların oluştuğu da belirtilmiştir. Bu kişiler, internet karşısında zaman kavramlarını yitirmekte ve bütün günün nasıl geçtiğini anlamayacak kadar oyuna odaklanmaktadırlar. Bireyler uykusuzluk, hareketsizlik, hareketsizliğe bağlı kilo alma, dengesiz beslenme gibi olumsuzluklarla karşı karşıya kalmaktadır (Young ve ark., 2000).

Literatürde uzun süre bilgisayar oyunu oynayan kişiler el ve ayak reaksiyon hızları ile ilişkili bir çalışmaya rastlanmamıştır. Bu doğrultuda çalışmanın amacı, uzun süre oyun oynayan bireylerde meydana gelen uyku, fiziksel aktivite düzeyi ile el ve ayak reaksiyon zamanı arasındaki ilişkiyi değerlendirmektir. Çalışmamızın temel sorusu; bilgisayar oyunu oynama süresinin fiziksel aktivite, tepki hızı (reaksiyon zamanı) ve uyku kalitesini bilgisayar başında uzun süre hareketsiz kalması sonucunda ve bilgisayar yardımcı araçlarının (klavye, mouse, joistik) kullanımı dolayısıyla azalıp azalmadığını test etmektir. Çalışmanın hipotezleri ise, bilgisayar oyunu oynama süresinin uyku kalitesi, reaksiyon zamanı ve fiziksel aktivite düzeyi arasında ilişki yoktur veya bilgisayar da uzun süre oyun oynamak uyku kalitesini, reaksiyon zamanı ve fiziksel aktivite arasında da anlamlı fark vardır olarak belirlenmiştir.

\section{Yöntem}

Çalışmaya 31 oyun oynayan (19E,12K) ile oyun oynamayan 30 kişi (16K,14E) 2 grup incelemeye alınmıştır. Kas-iskelet sistemini etkileyen herhangi bir rahatsızlığı olmayan ve psikiyatrik hastalığı bulunmayan bireyler çalışmaya dahil edilmiştir. Sistemik veya doğuştan rahatsızlığı olan, nörolojik hastalığı olan, 3 ay içerisinde cerrahi operasyon geçirmiş olan, fiziksel aktivite düzeyini etkileyecek problemi veya hastalığı olan ve düzenli ilaç kullanan (oral kontraseptif tedavi dahil) bireyler çalışmaya dahil edilmemiştir. Bu çalışma için Üsküdar Üniversitesi Etik Kurulu tarafından kabul edilen etik kurul sözleşmesi katılımcılara okunarak imzalatıııştır (B.08.6.YÖK.2.ÜS.0.05.0.06/2018/420). Veriler SPSS 25 paket programı kullanılarak analiz edilmiştir. Kişilerin demografik ve fiziksel özellikleri değerlendirirken frekans, aritmetik ortalama \pm standart sapma değerleri hesaplanmıştır. Oyun oynayan ve oynamayan grubun, karşılaştırılmalı fiziksel aktivite, uyku kalitesi ve reaksiyon zamanı değerleri Bağımsız $t$ testi kullanılarak karşılaştırılmıştır. Oyun oynama zamanının; fiziksel aktivite, uyku kalitesi ve reaksiyon zamanına etkisi korelasyon 
testiyle karşılaştırılmıştır. Yapılan analizlerin anlamlılık düzeyi $p<0,05$ olarak kabul edilmiştir.

Demografik bilgiler: Oyun oynayan ve oynamayan gruplara ait fiziksel özellikler Tablo 1'de gösterilmiştir. Tabloya göre katılımcılar arasında oyun oynayan kişilerin ortalama boyu 174,642 cm; ortalama kiloları 75,516; ortalama yaşları 23,096 ve vücut kitle indeksleri ise 23,9613'tür. Bu değerler oyun oynamayan kişiler açısından ele alındığında ise ortalama boyları 177,1724; ortalama kiloları 75,517; ortalama yaşları 23,5517 ve ortalama vücut kitle indeksleri ise 22,512'dir.

Tablo 1. Oyun oynayan ve oynamayan grubun fiziksel özellikleri

\begin{tabular}{c|c|c|c}
\hline & $\begin{array}{c}\text { Oyun oynayan kişiler } \\
\text { Ortalama } \pm \text { SS }\end{array}$ & $\begin{array}{c}\text { Oyun oynamayan kişiler } \\
\text { Ortalama } \pm \text { SS }\end{array}$ & P \\
\hline Boy $(\mathrm{cm})$ & $174,642 \pm 6,514$ & $177,1724 \pm 7,076$ & 0,145 \\
\hline Kilo(kg) & $75,516 \pm 6,438$ & $75,517 \pm 11,2490$ & 0,267 \\
\hline Yaş(yıl) & $23,096 \pm 2,005$ & $23,5517 \pm 2,1642$ & 0,563 \\
\hline Vki(kg/m2) & $23,9613 \pm 2,067$ & $22,512 \pm 2,56402$ & 0,282 \\
\hline
\end{tabular}

Ort: Ortalama; SD: Standart sapma; Kg: Kilogram; Cm: Santimetre; VKi: Vücut kitle indeksi

Aşağıdaki Şekil 1 ve Şekil 2'de ise katıımcıların bilgisayar kullanım sürelerine göre hafif, orta ve ağır kullanıcı oldukları ve hangi türde oyunları oynadıkları gösterilmiştir. Çalışmamıza dahil edilen katıımcıların \%38'i oyun oynamamaktadır ve oyun oynayan kişilerin tarafından en çok tercih edilen oyun MMORPG (Online-çoklu oyunculu çevrimiçi oyunlar)'dir. Ayrıca oyun oynayan kişilerin \%23'ü macera, \%20'si savaş strateji, \%8'i rol yapma oyunlarını tercih etmektedir (Şekil 2). MMORPG online oyun oynayan kişilerin \%13.3'ü hafif (<1 saat), \%40.1'i orta (1-4 saat) ve \%46,6'sı ağır (4 saat<) kullanıcılardan oluşmaktadır (Şekil 1).

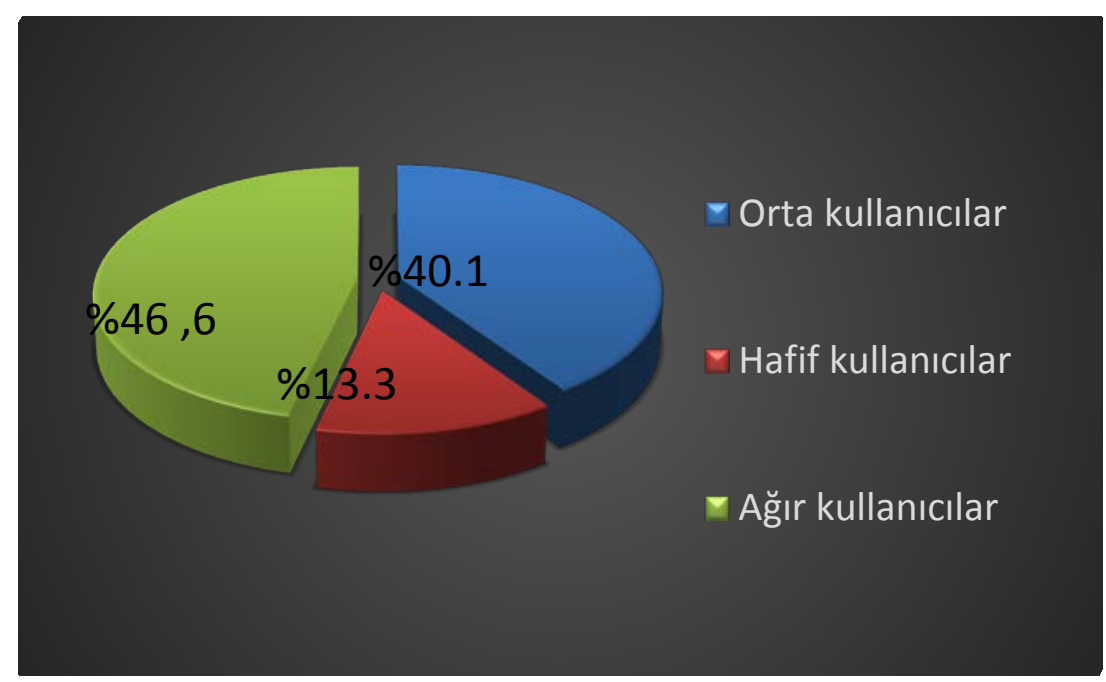

Şekil 1.Oyun oynama zamanına göre kullanıcıların oran grafiği 


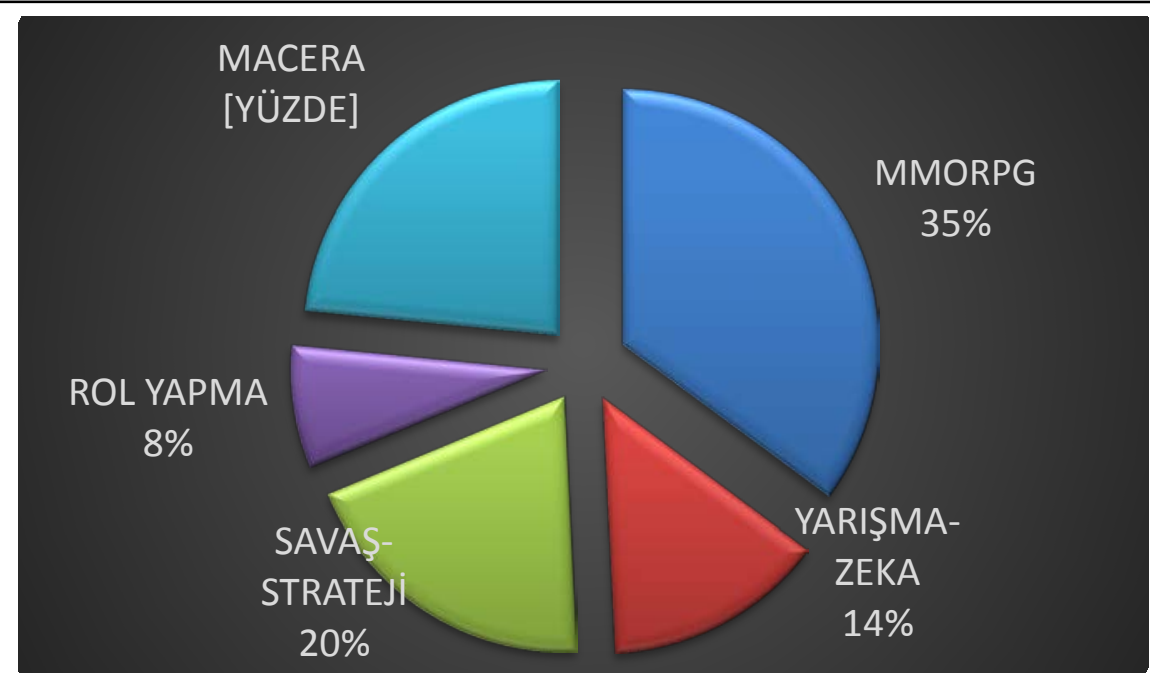

Şekil 2. Oyun oynayan kişilerin oyun çeşitlerini oynama yüzdeleri grafiği

Reaksiyon Zamanı Değerlendirilmesi: Reaksiyon zamanı değerlendirilmesi amacıyla Nelson el reaksiyon testi ve Nelson ayak testi uygulanmıştır. Nelson el reaksiyon testi doğrultusunda, deneklerden ön kol ve el, masanın üzerinde rahat olacak biçimde sandalyeye oturması istenmiştir. Başparmak ve işaret parmak uçları masadan 8-10 cm dışarıda başparmak ve işaret parmağının üst kısımları birbirine paralel olacak şekilde hazır duruma getirilmiştir. Test yöneticisi cetveli, deneğin baş ve işaret parmaklarının arasında olacak şekilde tutarak, deneğin direkt olarak cetvelin orta noktasına bakması ve cetvel bırakıldığında deneğin cetveli yakalaması istenmiştir. Deneğin cetveli yakaladığı başparmağının üst kenarında bulunan değer okunarak kaydedilmiştir. Beş tekrar sonucunda en iyi ve en kötü ölçüm değerleri atılarak geriye kalan üç ölçümün ortalaması cetvelin düştüğü mesafe olarak kaydedilmiştir. Nelson ayak testi; denek ayakucu $2.5 \mathrm{~cm}$, topuk kısmı $5 \mathrm{~cm}$ olacak şekilde duvar karşısına oturması istenmiştir. Test yöneticisi reaksiyon cetvelini duvar ile deneğin ayağı arasında olacak şekilde tutup ve denek hazır olduğu anda cetveli bırakmıştır. Denek, düşen cetveli ayakucu ile duvara sıkıştırılarak tutması istenmiştir. Topuğun üst kenarında bulunan değer okunarak kaydedilmiştir. Beş tekrar sonucunda en iyi ve en kötü ölçüm değerleri atılarak geriye kalan üç ölçümün ortalaması cetvelin düştüğü mesafe olarak kaydedilmiştir.

Uyku Kalitesi Değerlendirilmesi: Gönüllülerin uyku kalitesine Pittsburgh uyku kalitesi ölçeği (PUKi) ile bakılmıştır. PUKi ölçeği Buysse ve ark.(1989) tarafından geliştirilmiş ve Türkiye'ye çevrilip uyarlanmasını ise, Ağargün ve ark.(1996)'ları gerçekleştirmiştir. PUKi ölçeği, iyi ve kötü uykunun tanımlanması amacıyla uyku kalitesinin niceliksel ölçümünü veren toplam 24 soruluk bir ölçektir. PUKi ölçeği, uyku 
bozukluğu olup olmadığını ya da uyku bozukluklarının yaygınlığını göstermemektedir. Ölçekte kullanılan 24 sorudan 19'u bireyin kendisi tarafından cevaplanırken, diğer 5 soru bireyin eş veya bir oda arkadaşı tarafından yanıtlanmaktadır.

Ölçeğin puanı hesaplanırken bireyin eş veya oda arkadaşı tarafından yanıtlanan sorular hesaplamaya dahil edilmez. Kendini değerlendirme soruları, uyku kalitesi ile ilgili değişik maddeleri içerir. Bunlar uyku süresini, uyku latansını (gecikmesini) ve uyku ile ilgili özel problemlerin sıklık ve şiddetini saptamak içindir. Puanlanan 18 madde 7 bileşen puanı şekilde gruplandırılmıştır. Bileşenlerin bazıları tek bir maddeden oluşmakta, bazıları ise birkaç maddenin gruplandırılması ile elde edilmektedir. Her madde 0-3 arasında puanla değerlendirilir. Bu bileşenler; PUKi öznel uyku kalitesi, uykuda gecikme, uyku bozulmaları, uyku ilacı kullanımı ve gün içerisinde içindeki işlev bozukluğu olarak yedi alt öğeden oluşmaktadır. Bu yedi bileşenin puanın toplanması ile toplam ölçek puanını 0-21 değerleri arasında hesaplanır. Toplam puanın 5 ve üzerinde olması uyku kalitesinin kötü olduğunu göstermektedir.

Fiziksel Aktivite Değerlendirilmesi: Gönüllülerin fiziksel aktivite değerlendirilmesini yapmak için Uluslararası fiziksel aktivite ölçeği (IPAQ) kullanılmıştır. Bu ölçek yetişkinlerin fiziksel aktivite düzeylerini tespit etmek amacıyla kısa ve uzun form olarak tasarlanmıştır. Oluşturulan bu ölçeğin geçerlilik ve güvenilirliği Craig ve ark. (2003) tarafından gerçekleştirilmiş, Türkiye'de geçerlilik ve güvenilirliği ise Öztürk ve ark. (2005) tarafından gerçekleştirilmiştir. Anket son 7 günde en az 10 dakika yapılan fiziksel aktivite sorularını içeren 4 ayrı bölümden oluşmaktadır. Yaşları 18-69 yıl arasında değişen yetişkinlere uygulanması tavsiye edilmektedir. Ankette son haftada kaç gün ve her bir gün için ne kadar süre ile a) Ağır fiziksel aktiviteler (AFA), b) Orta yoğunlukta fiziksel aktiviteler (OFA), c) Yürüyüş $(Y)$ yapıldığını belirlenmektedir. Ölçeğin son sorusunda ise günlük olarak hareket etmeden (oturarak, yatarak vs.) harcanan zaman belirlenmektedir. Fiziksel aktivite düzeyini belirlemek için metabolik eşdeğer (MET) yöntemi kullanılmaktadır. $1 \mathrm{MET}=3,5 \mathrm{ml} / \mathrm{kg} / \mathrm{dk}$. İstirahat halinde iken her kişi bir kg başına bir dakikada 3,5 ml oksijen tüketmektedir. IPAQ'ta, AFA=8,0 MET, OFA=4,0 MET, $Y=3,3$ MET olarak harcandığını kabul edilmektedir. Her bir kişinin haftada kaç gün ve ne kadar süre ile AFA, OFA ve $Y$ yaptığını tespit ederek bu üç farklı fiziksel aktiviteden harcanan toplam MET miktarı hesaplanmaktadır. Fiziksel Aktivite düzeyi 3 kategoride belirlenmektedir. 
- Birinci kategori: Hafif: $<600 \mathrm{MET}-\mathrm{min} / \mathrm{hf}$

- Íkinci kategori: Orta: $>600-3000 \mathrm{METmin} / \mathrm{hf}$

- Üçüncü kategori: Ağır: <3000 METmin/hf.

\section{Bulgular}

Yapılan çalışmanın güvenilirliğini test etmek için gerçekleştirilen güvenilirlik analizi sonucunda aşağıdaki tabloda gösterilmiştir. Tabloda bakılması gereken nokta ise cronbach's alpha değeridir. Özdamar (2004)'a göre, Alfa katsayısının ( $\alpha$ ) değerlendirilmesinde;

$\cdot 0,00 \leq \alpha<0,4$ ise ölçek güvenilir değildir.

$\cdot 0,4 \leq \alpha<0,6$ ise ölçek düşük güvenilirliktedir.

$\cdot 0,6 \leq \alpha<0,8$ ise ölçek oldukça güvenilirdir.

- $0,8 \leq \alpha<1$ ise ölçek yüksek derecede güvenilir bir ölçektir.

Bu doğrultuda yapılan çalışmanın güvenilirlik değeri 0,877 çıkmış ve yüksek derecede güvenilir bir ölçek olduğu söylenebilir.

Tablo 2. Güvenilirlik Testi (Reliablity Statistics)

\begin{tabular}{r|r}
\hline Cronbach's Alpha & N of Items \\
\hline, 877 & 61 \\
\hline
\end{tabular}

Oyun çeşitlerine göre; oyun oynayan kişi, oyun başında geçirilen ortalama süre, fiziksel aktivite, uyku kalitesi, el ve ayak reaksiyon zamanı ortalama değerleri aşağıdaki tabloda gösterilmiştir.

Tablo 3. Oyun çeşitlerine göre bağımsız değişkenlerin ortalama değerleri

\begin{tabular}{cccccc}
\hline $\begin{array}{c}\text { Oyun } \\
\text { çeşidi }\end{array}$ & $\begin{array}{c}\text { Kişi } \\
\text { sayısı }\end{array}$ & $\begin{array}{c}\text { Ort. } \\
\text { Süre }\end{array}$ & $\begin{array}{c}\text { Ort. Fiziksel } \\
\text { aktivite }\end{array}$ & $\begin{array}{c}\text { Ort. Uyku } \\
\text { kalitesi }\end{array}$ & $\begin{array}{c}\text { Ort. El } \\
\text { reaksiyonu }\end{array}$ \\
\hline MMORPG & 15 & 4.5 & 946,36 & 6.4 & 0.0192 \\
Diğer & 16 & 2.125 & 1035,69 & 6.3 & 2.0266 \\
oyunlar & & 0 & 1144.803 & 5,931 & 0,0340 \\
Yok & 29 & 0 & 62921,98 & 363 & 1,6965 \\
\hline Toplam & 60 & 105,5 &
\end{tabular}

$\mathrm{N}$ : Kişi sayısı; Ort: Ortalama

Yukarıdaki tabloda, oyun oynayan kişilerin oyun oynamayan kişilere göre fiziksel aktivite ortalamaları daha düşük olduğu görülmektedir. Ortalama fiziksel aktivite değerlerine bakıldığında MMORPG tarzı oyunları oynayan kişilerin ortalama fiziksel aktivitileri diğer oyunları oynayan kişilere göre daha düşük çıkmıştır. Bunun nedeni MMORPG tarzı oyunların daha fazla bağımlııı yaratması ve kişilerin daha uzun süreli olarak oyun oynamasının gerekli olması gösterilebilir. PUKi ölçeği doğrultusunda katııımcıların ortalama uyku kalitesi 5 'ten büyük olduğu için kalitesiz olduğu söylenebilir. Ancak uyku kalitesi iyiden kötüye doğru sıralandığında oyun 
oynayan kişiler, diğer oyun çeşitleri oynayanlar ve MMORPG tarzı oynayanlar şeklinde sıralanmaktadır. Ortalama el reaksiyon hızı kontrol edildiğinde ise MMORPG tarzı oyun oynayan kişilerin el reaksiyon hızının daha yüksek olduğu ancak oyun oynamayan kişilerin ise diğer oyunları oynayan kişilerden yüksek olduğu ortaya çıkmıştır.

Tablo 4. Oyun oynayan ve oynamayan kişi değerlerinin karşılaştırılması

\begin{tabular}{ccccc}
\hline & GRUPLAR & N & Ort.-SS & P \\
Fiziksel aktivite & Oynamayanlar & 29 & $1144.8034 \pm 411,7326$ & 0,927 \\
& Oynayanlar & 31 & $992,4694 \pm 282,29506$ & \\
& Oynamayanlar & 29 & $, 0341 \pm 0,00722$ & 0,010 \\
El reaksiyon zamanı & Oynayanlar & 31 & $, 0231 \pm 0,01561$ & \\
& Oynamayanlar & 29 & $5,931 \pm 2,1369$ & 0,588 \\
Uyku kalitesi & Oynayanlar & 31 & $6,35 \pm 2,346$ & \\
& Oynamayanlar & 29 & $, 0546 \pm 0,01966$ & \\
\hline \multirow{2}{*}{ Ayak reaksiyon zamanı } & Oynayanlar & 31 & $, 0585 \pm 0,02158$ & 0,588 \\
\hline
\end{tabular}

N: Kişi sayısı; Ort; ortalama; $\quad$ SS; Standart sapma; $p<0.05$

Yukarıdaki tabloya göre, oyun oynayan kişilerin fiziksel aktivite ortalamaları ve standart sapmaları 992,4694 $\pm 282,29506$ çıkmıştır. Bu değer oyun oynamayan kişilerin ise $1002,2842 \pm 404,44812$ şeklindedir. Oyun oynayan ve oynamayan grupların fiziksel aktiviteleri arasındaki ilişki ise anlamsız çıkmıştır $(0,927>0,005)$. Oyun oynayan kişilerin oyun oynamayan kişilere göre uyku kalitesi ortalaması daha düşük bulunmuştur. Oyun oynayan kişilerin uyku kalitesi puanı ortalama ve standart sapması 6,26 $\pm 2,423$ 'tür. Oyun oynamayan kişilerin uyku kalitesi ortalama ve standart sapması ise 6,35 $\pm 2,346$ 'dır. Oyun oynayan ve oynamayan grupların uyku kaliteleri arasındaki anlamlı bir ilişki olmadığı ortaya çıkmıştır $(0,588>0,005)$. Oyun oynayan kişilerin oyun oynamayan kişilere göre el reaksiyon zamanları daha düşük yani tepkime süresi daha az olduğu ortaya çıkmıştır. Oyun oynayan kişilerin el reaksiyon zamanı ortalama ve standart sapmaları 0,0231 \pm 0,01561'dir. Oyun oynamayan kişilerde ise el reaksiyon zamanı ortalama ve standart sapması 0,0314 \pm 0,00515 'tir. Oyun oynayan ve oynamayan grupların el reaksiyon zamanları arasında anlamlı bir ilişki saptanmıştır $(0,01<0,005)$. Oyun oynayan kişilerin ayak reaksiyon zamanı oynamayan kişilere göre daha düşük çıkmıştır. Oyun oynayan kişilerin ayak reaksiyon zamanı ortalama ve standart sapmaları 0,0585 \pm 0,02158'dir. Oyun 
oynamayan kişilerin ise $0,0576 \pm 0,02229$ 'dur. Oyun oynayan ve oynamayan grupların ayak reaksiyon zamanları arasında ilişki bulunmamıştır $(0,588>0,005)$.

Katııımcıların oyun oynama süresi ile ortalama fiziksel aktivelerinin karşılaştırılması ve bu iki değişken arasındaki ilişkiler aşağıdaki tabloda gösterilmiştir.

Tablo 5. Oyun oynama süresi ile fiziksel aktivite arasındaki ilişki

\begin{tabular}{ccc}
\hline Oyun oynama süresi & Ort. Fiziksel aktivite- SS & P değeri \\
\hline Hafif $(\mathbf{n}=\mathbf{1 3})$ & $1056,614 \pm 253,693$ & 0,554 \\
Orta $(\mathbf{n = 8})$ & $985,212 \pm 245,2125$ & 0,423 \\
Ağır $(\mathbf{n = 1 0})$ & $914,887 \pm 346,74161$ & 0,367 \\
\hline
\end{tabular}

N: Kişi sayısl; Ort; ortalama; SS; Standart sapma; $\quad p<0.05$

Tabloya göre, oyun oynayan kullanıcıların fiziksel aktivite ortalaması ve standart sapması sırasıyla; ağır kullanıcılar: $914,887 \pm 346,74161$; orta kullanıcılar: $985,212 \pm 245,2125$; hafif kullanıcılar: 1056,614 $\pm 253,693$ şeklindedir. Oyun oynama süresi açısından kişilerin hafif, orta veya ağır kullanıcı olmaları ile ortalama fiziksel aktivite arasında anlamlı bir ilişki olmadı ortaya çıkmıştır.

Aşağıdaki tabloda Katııımıların oyun oynama süresi ile ortalama uyku kalitesinin karşılaştırıması ve bu iki değişken arasındaki ilişki gösterilmiştir.

Tablo 6. Oyun oynama Süresi ile Uyku Kalitesi arasındaki ilişki

\begin{tabular}{ccc}
\hline Oyun oynama süresi & Ort. Uyku kalitesi -SS & P değeri \\
\hline Hafif kullanıcı $(\mathbf{n = 1 3 )}$ & $6.153 \pm 2.67$ & 0,512 \\
Orta kullanıcı $(\mathbf{n = 8})$ & $5.5 \pm 1.69031$ & 0,405 \\
Ağır kullanıcı $(\mathbf{n = 1 0})$ & $7,3 \pm 2.21359$ & 0,687 \\
\hline
\end{tabular}

N: Kişi sayısı; Ort: ortalama; SS: Standart sapma; $p<0.05$

Oyun oynayan kullanıcıların uyku kaliteleri ortalama ve standart sapması sırasıyla ağır kullanıcılar: $6.153 \pm 2.67$, orta kullanıcılar: $5.5 \pm 1.69031$ ve hafif kullanıcılar: $7,3 \pm 2.21359$ 'dur. Oyun oynama süresi ile uyku kalitesi arasında anlamlı bir ilişki olmadığı ortaya çıkmıştır $(p>0,005)$. Aşağıdaki tabloda katılımcıların oyun oynama süresi ile ortalama el reaksiyon zamanı karşılaştırılması ve bu iki değişken arasındaki ilişki gösterilmiştir.

Tablo 7. Oyun oynama süresi ile el reaksiyon zamanı arasındaki ilişki

\begin{tabular}{ccc}
\hline Kullanıcı & El-reaksiyon Ort.-SS & P değeri \\
\hline Hafif kullanıcı $(n=13)$ & $\mathbf{0 , 0 3 3 4 \pm 0 , 0 0 4 7 3}$ & $\mathbf{0 , 0 3 4}$ \\
Orta kullanıcı $(n=8)$ & $0,262 \pm 0,2090$ & 0,026 \\
Ağır kullanıcı $(n=10)$ & $\mathbf{0 , 0 0 7 2 \pm 0 , 0 0 1 1 7}$ & $\mathbf{0 , 1 5}$ \\
\hline
\end{tabular}


N: Kişi sayısı; Ort; ortalama; SS; Standart sapma; $p<0.05$

Oyun oynayan kullanıcıların ortalama el reaksiyon zamanı ve standart sapmaları sırasıyla ağır kullanıcılar: 0,0072 \pm 0,00117, orta kullanıcılar: 0,262 \pm 0,2065 ve hafif kullanıcılar: 0,0334 \pm 0,00473'tür. Oyun oynama süresi ile el reaksiyon zamanı arasında hafif ve orta kullanıcılar arasında anlamlı bir ilişki varken ağır kullanıcılar ile ortalama el reaksiyon hızında anlamlı bir ilişki olmadığı ortaya çıkmıştır $(0,15>0,05)$.

Aşağıdaki tabloda katılımcıların oyun oynama süresi ile ortalama ayak reaksiyon zamanı karşılaştırılması ve bu iki değişken arasındaki ilişki gösterilmiştir.

Tablo 8. Oyun oynama süresi ile ayak reaksiyon zamanı arasındaki ilişki

\begin{tabular}{ccc}
\hline Oyun oynama süresi & Ayak -reaksiyon Ort.-SS & P değeri \\
\hline Hafif kullanıcı $(\mathbf{n = 1 3})$ & $0,0566 \pm 0,02458$ & 0,406 \\
Orta kullanıcı $(\mathbf{n}=\mathbf{8})$ & $0,0532 \pm 0,01644$ & 0,512 \\
Ağır kullanıcı $(\mathbf{n}=10)$ & $0,0664 \pm 0,0664$ & 0,375 \\
\hline
\end{tabular}

N: Kişi sayısı; Ort; ortalama; SS; Standart sapma; $p<0.05$

Tabloya göre, oyun oynayan kişilerin ayak reaksiyon zamanı ortalama ve standart sapmaları sırasıyla ağır kullanıcılar: 0,0664 \pm 0,0664, orta kullanıcılar: $0,0532 \pm 0,01644$, hafif kullanıcılar ise: 0,0566 $\pm 0,02458$ 'dir. Oyun oynama süresi ile ayak reaksiyon zamanı arasında anlamlı bir ilişki saptanmamıştır ( $p>0,005)$.

Çalışma hipotezlerinden biri olan fiziksel aktive ile el reaksiyon zamanı arasındaki ilişkiyi kontrol etmek için bu iki değişken arasında Bağımsız t Testi gerçekleştirilmiştir ve analiz sonuçları aşağıdaki tabloda gösterilmiştir.

Tablo 9. Fiziksel aktivite ile el reaksiyon zamanı arasındaki ilişki

\begin{tabular}{ccc}
\hline Fiziksel aktivite seviyesi & Ort. El reaksiyon & P değeri \\
\hline Hafif $(\mathbf{n}=\mathbf{1 3}$ kişi) & $0.0222 \pm 0,0185$ & 0,257 \\
Orta $(\mathbf{n}=\mathbf{4 7}$ kişi) & $0,0242 \pm 0,0174$ & 0,265 \\
Ağır $(\mathbf{n}=\mathbf{0}$ kişi) & - & - \\
\hline
\end{tabular}

N: Kişi sayısı; Ort; ortalama; SS; Standart sapma; $p<0.05$

Katılımcılardan toplanan veriler doğrultusunda kişilerin 13'ü sedanter, 47'si orta aktif iken çok aktif kişi sayısı sıfır olarak tespit edilmiştir. Oyun oynayan kişilerin fiziksel aktivite ile el reaksiyon zamanı arasında anlamlı bir ilişki çıkmamıştır $(p>0,005)$. Fiziksel aktivite sıralamalarına göre el reaksiyon zamanı ortalama ve standart sapmaları sedanter kişiler: $0.0222 \pm 0,0185$ ve orta aktif kişiler ise 0,0242 \pm 
0,0174'tür. Elde edilen veriler doğrultusunda fiziksel aktivite ile uyku kalitesi arasındaki ilişkinin analiz sonuçları aşağıdaki tabloda gösterilmiştir.

Tablo 10. Fiziksel aktivite ile uyku kalitesi arasındaki ilişki

\begin{tabular}{ccc}
\hline Fiziksel aktivite seviyesi & Ort. Uyku kalitesi -SS & P değeri \\
\hline Hafif ( $\mathbf{n = 1 3}$ kişi) & $6.153 \pm 2.67$ & 0,500 \\
Orta ( $\mathbf{n}=\mathbf{4 7}$ kişi) & $8 \pm 1.69031$ & 0,376 \\
Ağır ( $\mathbf{n}=\mathbf{0}$ kişi) & - & - \\
\hline
\end{tabular}

N: Kişi sayısı; Ort; ortalama; SS; Standart sapma; $p<0.05$

Oyun oynayan kişilerin fiziksel aktivite ile uyku kalitesi arasında anlamlı bir ilişki olmadığı ortaya çıkmıştır ( $p>0,005)$. Fiziksel aktivite sıralamalarına göre uyku kalitesi ortalama ve standart sapmaları sedanter aktif kişiler: 5,66 \pm 3.22 , orta aktif kişiler: 6,36 \pm 4.11 ve katılımcılar arasında çok aktif kişi bulunmamaktadır.

\section{Tartışma}

$\mathrm{Bu}$ çalışma bilgisayar başında uzun süre oyun oynamanın fiziksel aktivite, uyku kalitesi ve reaksiyon zamanı arasındaki ilişkiyi test etmek amacıyla planlanmıştır. Çalışma sonucunda elde edilen en önemli bulgu oyun oynama süresinin artması ile el reaksiyon zamanının azalmasıdır. Reaksiyon zamanının yapılan iş ile azalması, genel olarak el ve parmakların sık kullanıldığı aktivitelerde çok sık rastlanılan bir durumdur. Bu çalışmanın örneklemi olan e-sporcularda bu durumu destekleyen sonuçlar elde edilmiştir. Bilgisayar oyunu oynayan kişiler, klavye, joistik ve diğer donanımlar sürekli olarak kullanmaktadırlar. Bilgisayara ait bu yardımcı elemanlar, el ve parmak kullanımını artırdığı için kişilerde el reaksiyon hızlarının arttığı söylenebilir. Artan bilgisayar kullanımının, gençlerde kas ve iskelet sisteminin gelişimini etkilediği ayrıca fiziksel aktiviteyi azaltması doğrudan veya postürel alışkanlıkları değiştirmesi nedeniyle dolaylı olarak kas-iskelet sistemi rahatsızlıkları riskini artırdığı gözlenmektedir (Straker ve ark., 2007; Akçay, 2017).

Çalışmamızda fiziksel aktivitenin oyun oynama süresi ile azalmaması, çalışmamıza katılan kişilerde değerlendirdiğimiz bağımsız değişkenlerin tam olarak bu verileri yansıtmaması ve bu kişilerin mesleki açıdan farklı gruplarda olması veya izole olarak bilgisayar işi veya oyunlarla uğraşmadıkları şeklinde açıklanabilir. Oyun oynayan bireylerde, oyun oynama süresinin artması ve oyunların kişilerde yarattığı bağımlılık etkisi kişilerin uykularından ciddi tavizler vermesine sebep olmaktadır. Günümüzde üniversite öğrencileri ile yapılan çalışmaların bir çoğunda uyku 
bozukluklarına rastlanmaktadır (Greig ve ark., 2005). Çalışmamız da uyku kalitesini oyun oynama süresi ile karşılaştırdığımızda anlamlı fark ortaya çıkmamıştır. Bu farklıı̆ın ortaya çıkmamasına neden olarak örneklemin yetersiz olması veya örnekleme dahil olan kişilerin yeterli/doğru cevaplar vermemesi olabilir. İsveçli çocuklar üzerinde yapılan $(n=616)$ bir araştırmada, uyku bozukluğu ile yatak odasında TV, bilgisayar gibi teknolojik cihazların bulunması, TV ya da bilgisayarın başında 2 saatten fazla vakit geçirme arasında ilişki saptanmıştır (Akçay, 2017). Yaptığımız çalışmada da oyun oynayan kişiler ile oynamayan kişiler arasında uyku kalite indeksi sonucunda oyun oynamayan kişilerin uyku kalitesinin daha iyi uyku alışkanlıklarının ise daha düzenli olduğu ortaya çıkmıştır.

Konuyla ilgili alanda yapılan araştırmalara göre, Avustralya'da çocukların \%99'unun 11-14 yaşları arasında bilgisayar kullanmaya başladığını, Amerika Birleşik devletlerinde ise çocukların günde 60 dakikadan fazla bilgisayar karşısında vakit harcadıklarını ve ergenlerin (11-18) \%64'ünün bilgisayar kullandığını göstermiştir (Tamer, 2000). Çalışmamıza katılan bireylerin \%62'si oyun oynamakta ve bu kişilerin hepsi günde 1 saatten fazla bilgisayar başında kalmaktadırlar.

Çalışmamızda oyun çeşidi ile oyun oynama süresi arasında doğrudan bir ilişki bulunmuştur. Oyun çeşidi, özellikle online çevrimiçi oyunlar olduğunda (MMORPG) kişileri ciddi oranda bilgisayar başında vakit geçirmektedir. Çok tercih edilen devasa çok oyunculu online oyunlar (MMORPG), aynı anda yüzbinlerce oyuncunun dahil olabildiği, oyuncuların karşııklı olarak birbirleriyle dünyanın farklı ülkelerinden insanlarla karşılıklı iletişim kurmalarına imkân sağlayan bilgisayar oyunlarıdır (Gürcan ve ark., 2008). Uzun süre kontrolsüz bir şekilde masa başında bilgisayar ve internet kullanımı çocuk/gencin fiziksel, psikolojik, sosyal, bilişsel sağlığını olumsuz yönde etkilemektedir (Kuzu vd., 2008).

Çalışmamızda oyun çeşidi özellikle MMORPG yani günümüzde oynanan online çoklu çevrimiçi oyunlar ile bu oyun başında geçirilen zamanın çok fazla olduğu gözlenmiştir. Fakat bireylerin bu oyunlar içerisinde kalma süresinin etkileyen diğer faktörlerin hepsini sorgulayacak çalışmalara intiyaç vardır. Literatürde bu kişiler de bedensel sağlık faktörlerinin değerlendirildiği çalışmalara intiyaç olduğu kanaatindeyiz. 


\section{Sonuç}

Ankete katılan kişilerin oyun oynama süreleri ile fiziksel aktiviteleri arasında anlamlı bir ilişki çıkmamıştır. Bu kişilerin fiziksel aktivite ortalamaları 996.199'dur. Ankete katılan kişilerin oyun oynama süreleri ile uyku kaliteleri arasında anlamlı bir ilişki çıkmamıştır. Bu kişilerin uyku kalitelerini etkileyen faktör genel olarak yatakta geçirilen zaman ve verimsiz uyku ile ilişkilidir. Bu kişilerdeki uyku kalitesi ortalaması 6,32'dir (en yüksek 11; en düşük 2).

Ankete katılan kişilerin oyun oynama süreleri el reaksiyon zamanları arasında doğrudan anlamlı bir ilişki bulunmuştur. Oyun oynama süresi arttıkça kişilerin el reaksiyon kuvvetleri azalmaktadır ve yapılan Nelson el/ayak testi daha iyi sonuçlar almamıza yardımcı olmuştur. Bu kişilerin el reaksiyon zamanı ortalamaları 0,0262'dir. Çalışmamızda özellikle; bilgisayar başında oyun oynayan kişilerin el reaksiyon hızlarında artış gözlemlenmiştir. Bu kişilerin özellikle bilgisayar ile uğraşan veya bunu sürekli yapan kişiler olmamaları oyun oynama süresinin fiziksel aktivite ve uyku kalitesi ile ilişkilendirildiğinde anlamlı bir sonuç ortaya çıkmamıştır. Oyun oynama süresi ile fiziksel aktivite arasında anlamlı bir ilişki çıkmamasının nedeni ise fiziksel aktiviteyi etkileyen değişkenler içerisinde oyun oynama süresi dışında birçok bağımsız değişkenlerin (iş hayatı, uyku kalitesi, yaş vb.) modelde yer almamasıdır.

Çıkan sonuçları etkileyen birçok bağımsız değişken (meslek, yaş, cinsiyet vb.) araştırmanın fiziksel aktivite ve uyku kalitesi ile alakalı seyrini değiştirmiştir. Daha net bir sonuçlara ulaşmak için araştırmanın sadece bilgisayar oyunu ile uğraşan ya da bunu iş olarak yapan kişilerde bakılmasının gerekli olduğu kanaatindeyiz.

\section{Kaynaklar}

Ağargün MY, Kara H, Anlar O.(1996). Pittsburgh Uyku Kalitesi İndeksi'nin Geçerliliği ve Güvenirliği. Türk Psikiyatri Derg. :107-11.

Akçay D. (2017). The Effect of Electronic Media Usage Children and Adolescents with Obesity and Sleep Problems, JCP 15(2):73-84 77.

Baltacı, G., Ersoy, G., Karaağaoğlu, N., Derman, O., Kanbur, N. (2008). Ergenlerde Sağlıklı Beslenme ve Hareketli Yaşam. T.C.Sağlık Bakanlığı Temel Sağlık Hizmetleri Genel Müdürlüğü Beslenme ve Fiziksel Aktiviteler Daire Başkanlığı. Fiziksel Aktivite Bilgi Serisi. Klasmat Matbaacılık, 74, Ankara. 
Buysse DJ, Reynolds CF, Monk TH. (1989). The Pittsburgh Sleep Quality Index: a new instrument for psychiatric practice and research. Psychiatry Res 1989;28:193- 213.

Craig CL, Mashall AL, Sjöström M, Bauman AE, Booth ML, Ainsworth BE. (2003). International physical activity questionnaire: 12-country reliability and validity. Med Sci Sports Exerc.;35:1381- 1395.

Daley AJ, Copeland RJ, Wright NP, Roalfe A, Wales JK. (2006). Exercise therapy as a treatment for psychopathologic conditions in obese and morbidly obese adolescents: a randomized, controlled trial. Pediatrics. 2006 Nov;118(5):212634.

Greig A, Straker L, Briggs A. (2005). Cervical erector spinae and upper trapezius muscle activity in children using different information technologies. Physiotherapy: 119-126.

Gürcan A, Özhan S, Uslu R. (2008). Dijital Oyunlar Ve Çocuklar Üzerindeki Etkileri. Ankara: Başbakanlık Aile ve Sosyal Araştırmalar Genel Müdürlüğü. 34.

Hazar Z ve Hazar M. (2017). Journal of Human Sciences, http://www.- jhumansciences.com, Erişim Tarihi: 14.12.2018

Kim, J H., Lau, C. H., Cheuk, KK., Kan, P., Hui, H., L. C.; Griffiths, S M. (2010). Brief Report: Predictors of Heavy Internet Use and Associations with HealthPromoting and Health Risk Behaviors among Hong Kong University Students. Journal Of Adolescence, 33, 215-220.

Kuzu, A., Odabaşı, F., Erişti, S. D., Kabakçı, I., Kurt, A. A., Akbulut, Y., Dursun, Ö. Ö., Kıyıcı, M., ve Şendağ, S. (2008). İnternet Kullanımı Ve Aile. Ankara: T. C. Başbakanlık Aile ve Sosyal Araştırmalar Genel Müdürlüğü Bilim Serisi: 133.

Mayda A.S., Yılmaz M., Bolu F., Dağıı Ç.S., Gerçek G.Ç., Teker N., Tiryaki S., Toygar G., Türkaslan M., Uslu A.M., Usturalı E., Yamansavcı E., Yardımcı N. ve Önder A.D. (2015). Bir Öğrenci Yurdunda Kalan Üniversite Öğrencilerindeki İnternet Bağımlıı̆ı İle Beck Depresyon Ölçeği Arasındaki İlişki. Konuralp Tıp Dergisi,7(1),1-5.

Özdamar, K., (2004). Paket Programlar ile İstatistiksel Veri Analizi 1, (5. Baskı), Kaan Kitabevi, Ankara.

Öztürk M. (2005) Üniversitede eğitim-öğretim gören öğrencilerde Uluslararası Fiziksel Aktivite Anketinin geçerliliği ve güvenirliği ve fiziksel aktivite düzeylerinin 
belirlenmesi. [Yayınlanmamış yüksek lisans tezi]. Ankara: Hacettepe Üniversitesi Sağlık Bilimleri Enstitüsü, Fizik Tedavi ve Rehabilitasyon Programı Straker, Leon M., Peter B. O'Sullivan Anne Smith, Mark Perry (2007). Computer Use and Habitual Spinal Posture in Australian Adolescents. Public Health Reports September - October 2007;122:634-643

Tamer K. (2000). Sporda Fiziksel-Fizyolojik Performansın Ölçülmesi ve Değerlendirilmesi. Ankara: Bağırgan Yayınevi. 104.

Young, K. S., Pistner, M., O'mara, J. ve Buchanan, J. (2000). Cyber-Disorders: The Mental Health Concern for the New Millennium. Cyberpsychology \& Behavior, 3(5), 475-479. 